\title{
Predicting compressive strength of different geopolymers by artificial neural networks
}

\author{
Ali Nazari ${ }^{\mathrm{a}, *}$, F. Pacheco Torgal ${ }^{\mathrm{b}}$ \\ ${ }^{a}$ Department of Materials Science, Saveh Branch, Islamic Azad University, Saveh, Iran \\ ${ }^{\mathrm{b}}$ University of Minho, C-TAC Research Centre, Guimarães, Portugal
}

Received 31 July 2012; received in revised form 19 August 2012; accepted 23 August 2012

Available online 1 September 2012

\begin{abstract}
In the present study, six different models based on artificial neural networks have been developed to predict the compressive strength of different types of geopolymers. The differences between the models were in the number of neurons in hidden layers and in the method of finalizing the models. Seven independent input parameters that cover the curing time, $\mathrm{Ca}(\mathrm{OH})_{2} \mathrm{content}$, the amount of superplasticizer, $\mathrm{NaOH}$ concentration, mold type, geopolymer type and $\mathrm{H}_{2} \mathrm{O} / \mathrm{Na}_{2} \mathrm{O}$ molar ratio were considered. For each set of these input variables, the compressive strength of geopolymers was obtained. A total number of 399 input-target pairs were collected from the literature, randomly divided into 279, 60 and 60 data and were trained, validated and tested, respectively. The best performance model was obtained through a network with two hidden layers and absolute fraction of variance of 0.9916 , the absolute percentage error of 2.2102 and the root mean square error of 1.4867 in training phase. Additionally, the entire trained, validated and tested network showed a strong potential for predicting the compressive strength of geopolymers with a reasonable performance in the considered range.

(c) 2012 Elsevier Ltd and Techna Group S.r.l. All rights reserved.
\end{abstract}

Keywords: Geopolymer; Compressive strength; Artificial neural networks; Modeling

\section{Introduction}

During recent years, the preparation of a geopolymeric matrix, an artificial synthetic aluminosilicate material, mainly three kinds of aluminosilicate sources were used including (i) natural metakaolin (calcined kaolin), (ii) fly ash and (iii) chemically synthesized metakaolin are used. The resultant geopolymers possess excellent properties including impressive acid and fire resistance, low production cost, environmentally friendly nature and good heat resistance properties $[1,2]$.

Ash-based geopolymers are a main group of geopolymeric materials. These are synthesized from various sources including fly ash [3-6], rice husk bark ash [7], slags [8,9], mine waste mud [10]. Although high strength is achieved by considering fly ashes as aluminosilicate source, their uncertain mixture (together with the altering reactive portion of these materials) make their use sensitive for critical purposes. However, the

\footnotetext{
*Corresponding author

E-mail address: alinazari84@aut.ac.ir (A. Nazari).
}

low final cost and waste management achievements could compensate this deficiency.

It has been reported that there is a large increase in the compressive strength of geopolymers formed from metakaolin through the addition of large quantities of silicon in a sodium-based alkali activating solution. The improvement in mechanical properties, correlated with the increase in the volume of geopolymeric gel at a relatively constant nominal density, resulting in a more homogenous microstructure. The change in microstructure is linked to the chemical processes occurring in the solution phase during reaction. It is known that geopolymers based on different alkali cation exhibit structural differences [11-14].

In the last years, artificial neural networks (ANNs) technology, a family of massively parallel architectures that solve difficult problems via the cooperation of highly interconnected but simple computing elements (or artificial neurons), is being used to solve a wide variety of problems in civil engineering applications $[10,15]$. "The most important property of ANNs in civil engineering problems is their capability of learning directly from examples. The 
other is their correct (or relatively correct) response to incomplete tasks, their extraction of information from noisy or poor data, and their production of generalized results from the novel cases. These mentioned capabilities make ANNs a very powerful tool to solve many civil engineering problems, particularly in situations, where data may be complex or in an insufficient amount [15]".

"The basic strategy for developing ANNs systems based models for material behavior is to train ANNs systems on the results of a series of experiments using the material in question. If the experimental results contain the relevant information about the material behavior, then the trained ANNs systems will contain sufficient information on the material's behavior to qualify as a material model. Such trained ANN systems not only would be able to reproduce the experimental results, but they would be able to approximate the results in other experiments trough their generalization capability [16]".

Numerous studies have been made concerning the prediction of the compressive strength of concrete using ANNs. For example, Özcan et al. [10] developed ANNs for the prediction of long-term compressive strength of silica fume concrete. Saridemir [15], predicted the compressive strength of concretes containing metakaolin and silica fume through ANNs. Topçu and Sarıdemir [16] used ANNs for evaluating the compressive strength of concrete containing fly ash. ANNs were also employed in Bilim et al. [17] work to investigate the compressive strength of ground granulated blast furnace slag concrete.

The authors' literature surveys show that the utilization of ANNs for predicting the different properties of geopolymers is limited to the applications revealed in the previous works, [18-20] for instance. Because of the limited research existing in the prediction of geopolymers properties through soft-computing techniques, the aim of this work is to develop suitable ANNs models for evaluating the compressive strength of different types of geopolymers. A total number of 399 pairs of input-target values were collected from the previous works [12,21,22]. The input parameters include the curing time, $\mathrm{Ca}(\mathrm{OH})_{2}$ content, the amount of superplasticizer, $\mathrm{NaOH}$ concentration, mold type, geopolymer type and $\mathrm{H}_{2} \mathrm{O} / \mathrm{Na}_{2} \mathrm{O}$ molar ratio. The compressive strength of geopolymers was considered as a single output parameter. Six different ANNs models were proposed for the prediction of the compressive strength of geopolymers. All of which had different numbers of neurons in hidden layers methods of finalizing. The entire models were trained, validated and tested by randomly divided 279, 60 and 60 input-target pairs, respectively.

\section{Data collection}

The input-target values were collected from the previous works $[12,21,22]$. The data collected in some manner that they contain different sources and mixture proportions of the constituent materials. In addition, a similarity between the collected data was considered so that they have waste materials as aluminosilicate source. The first series of data, with a total number of 180 , were the compressive specimens made from tungsten mine wastes [21]. Tungsten mine waste mud used was subjected to a thermal treatment at $950{ }^{\circ} \mathrm{C}$ during $2 \mathrm{~h}$. The fine aggregate used was a crushed sand from the same mine with a specific gravity of $2.7,24 \mathrm{~h}$ water absorption of $0.9 \%$, and a fineness modulus of 2.8 . Distilled water was used to dissolve the sodium hydroxide flakes to avoid the effect of unknown contaminants in the mixing water. The alkaline activator was prepared prior to use. The sand, mine waste mud and calcium hydroxide were dry mixed before adding the activator. To produce a workable mix extra water was added, and the mass ratio of water/dry solid content being $4 \%$. Compressive strength data was obtained using $50 \times 50 \times 50 \mathrm{~mm}^{3}$ cubic specimens, according to ASTM C109. The fresh mortar was cast and allowed to set at room temperature for $24 \mathrm{~h}$ before being removed from the moulds and kept at room temperature until tested in compression. The compressive strength for each mortar mixture was obtained from the average of 3 cubic specimens.

Metakaolin-based geopolymers investigated in Ref. [21] were the second source of this study, with 144 series of data. The metakaolin used in this study was subjected to a thermal treatment at $650{ }^{\circ} \mathrm{C}$ during a few seconds using a flash calcination apparatus. The factors considered in this investigation led to the manufacture of different mixes. The factors analyzed were, sodium hydroxide concentration $(10,12,14$ and $16 \mathrm{M})$, the superplasticizer content $(0 \%, 1 \%$, $2 \%$ and $3 \%$ ) and the percentage substitution of metakaolin by calcium hydroxide in the mixture $(5 \%$ and $10 \%)$. The mass ratio of sand/metakaolin/activator used was 2.2/1/1. The alkaline activator was prepared prior to use. An activator with sodium hydroxide and sodium silicate solution $\left(\mathrm{Na}_{2} \mathrm{O}=13.5 \%, \mathrm{SiO}_{2}=58.7 \%\right.$, and water $\left.=45.2 \%\right)$ was used with a mass ratio of 1:2.5. Again, distilled water was used to dissolve the sodium hydroxide flakes [12]. Alkali-activated mortars were a mixture of aggregates, metakaolin, calcium hydroxide and alkaline silicate solution. The sand, metakaolin and calcium hydroxide were dry mixed before added to the activator. No extra water was added. The compressive strength data was obtained using $160 \times 40 \times 40 \mathrm{~mm}^{3}$ cubic specimens according to EN 1015-11. The preparation method for compressive strength tests was similar to that of the previous work [12].

Finally, the third group of data was collected from geopolymers tungsten waste mud. The method of preparation of this waste material was similar to that of the previous work [12]. The mortar was a mixture of aggregates, waste mud, calcium hydroxide, alkaline silicate solution and water. The mass ratio of mine waste mud: activator was 1:1. Calcium hydroxide was used with a percentage substitution of $10 \%$, because it was found that this percentage leads to the highest compressive strengths. An activator with sodium hydroxide $(24 \mathrm{M})$ and sodium silicate solution $\left(\mathrm{Na}_{2} \mathrm{O}=8.6 \%, \mathrm{SiO}_{2}=27.8 \%, \mathrm{Al}_{2} \mathrm{O}_{3}=0.4 \%\right.$ and water $=$ $63.2 \%$ ) was used with a mass ratio of 1:2.5. Again, distilled 
Table 1

The range of input and output variables considered for ANN-I to ANNVI models.

\begin{tabular}{|c|c|}
\hline Variable & Range \\
\hline Curing time (days) & $1-90$ \\
\hline $\mathrm{Ca}(\mathrm{OH})_{2}$ content $(\mathrm{wt} \%)$ & $0-22.5$ \\
\hline The amount of superplasticizer (wt $\%$ ) & $0-3$ \\
\hline $\mathrm{NaOH}$ concentration $(M)$ & $6-24$ \\
\hline Mold type $^{a}$ & $1-2$ \\
\hline Geopolymer type $^{\mathrm{b}}$ & $1-3$ \\
\hline $\mathrm{H}_{2} \mathrm{O} / \mathrm{Na}_{2} \mathrm{O}$ molar ratio & $8.9-19.1$ \\
\hline Compressive strength $(\mathrm{MPa})$ & $1.5-75.2$ \\
\hline
\end{tabular}

a" 1 " and " 2 " were used for cubic mold type in accordance to ASTM C 109EN 1015-11 standards, respectively.

b، 1 ", "2" and "3" were employed for geopolymer type used in Refs. $[12,21,22]$, respectively. water was used to dissolve the sodium hydroxide flakes $[12,21]$. Compressive strength tests were conducted in a similar way to the method described earlier for Ref. [12] according to ASTM C 109 standard.

Table 3

The values of parameters used in neural network model.

\begin{tabular}{lc}
\hline Parameters & ANN \\
\hline Number of input layer units & 7 \\
Number of hidden layer & 2 \\
Number of output layer units & 1 \\
Momentum rate & 0.88 \\
Learning rate & 0.70 \\
Error after learning & 0.000050 \\
Learning cycle & 30.000
\end{tabular}

Table 2

Summary of ANNs for compressive strength value prediction.

\begin{tabular}{lcccc}
\hline Designation & \multicolumn{2}{l}{ Number of neurons in hidden layers } & Termination epoch & Termination state \\
\cline { 2 - 3 } & Hidden layer 1 & Hidden layer 2 & & \\
\hline ANN-I & 8 & 6 & 1000 & 1 \\
ANN-II & 10 & 8 & 1000 & 1 \\
ANN-III & 12 & 10 & 1000 & 1 \\
ANN-IV & 8 & 6 & 823 & 2 \\
ANN-V & 10 & 8 & 549 & 2 \\
ANN-VI & 12 & 10 & 471 & 2 \\
\hline
\end{tabular}

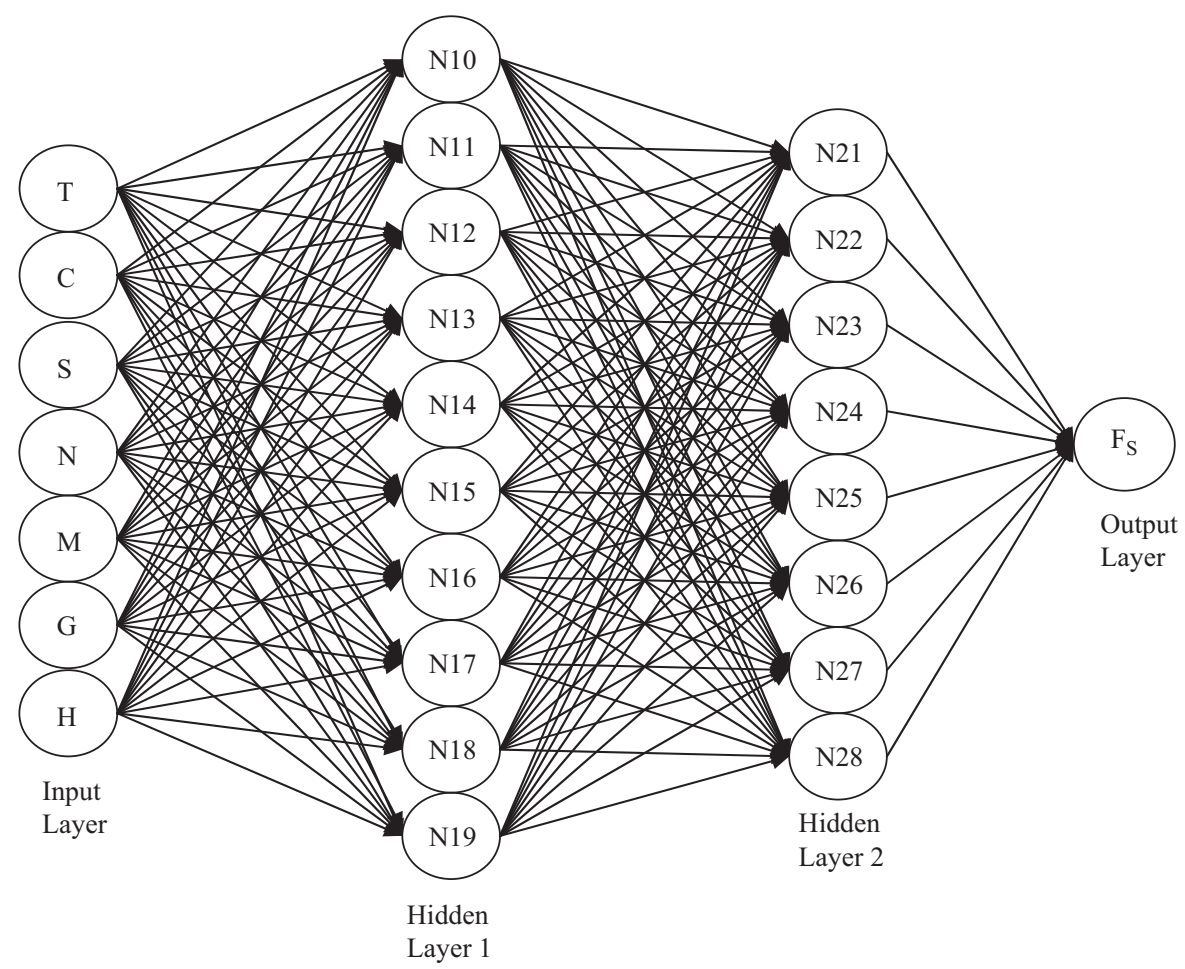

Fig. 1. The system used in the ANN-II model. 


\section{Artificial neural networks architecture}

"An artificial neural network (ANN) is a massively parallel, distributed information processing structure consisting of processing elements and many interconnections called connection weights between them. It resembles the brain in two respects; knowledge is acquired by the network through a learning process and interneuron connection weights known as synaptic weights are used to store the knowledge [10]".

According to Kong et al. [23], an artificial neuron is composed of five main parts: inputs, weights, sum function, activation function and outputs. The weighted sums of the input components (net) ${ }_{j}$ are calculated using Eq. (1) as follows [24]:

$(\text { net })_{j}=\sum_{i=1}^{n} W_{i j} x_{i}+b$

where (net) $)_{j}$ is the weighted sum of the $j$ th neuron for the input received from the preceding layer with $n$ neurons, $W_{i j}$ is the weight between the $j$ th neuron in the previous layer, $x_{i}$ is the output of the $i$ th neuron in the previous layer [24], $b$ is a fix value as internal addition and $\sum$ represents sum function. The activation function is one that processes the net input obtained from the sum function and determines the neuron output. The output of the $j$ th neuron (out) $)_{j}$ is computed using Eq. (2) with a sigmoid activation function
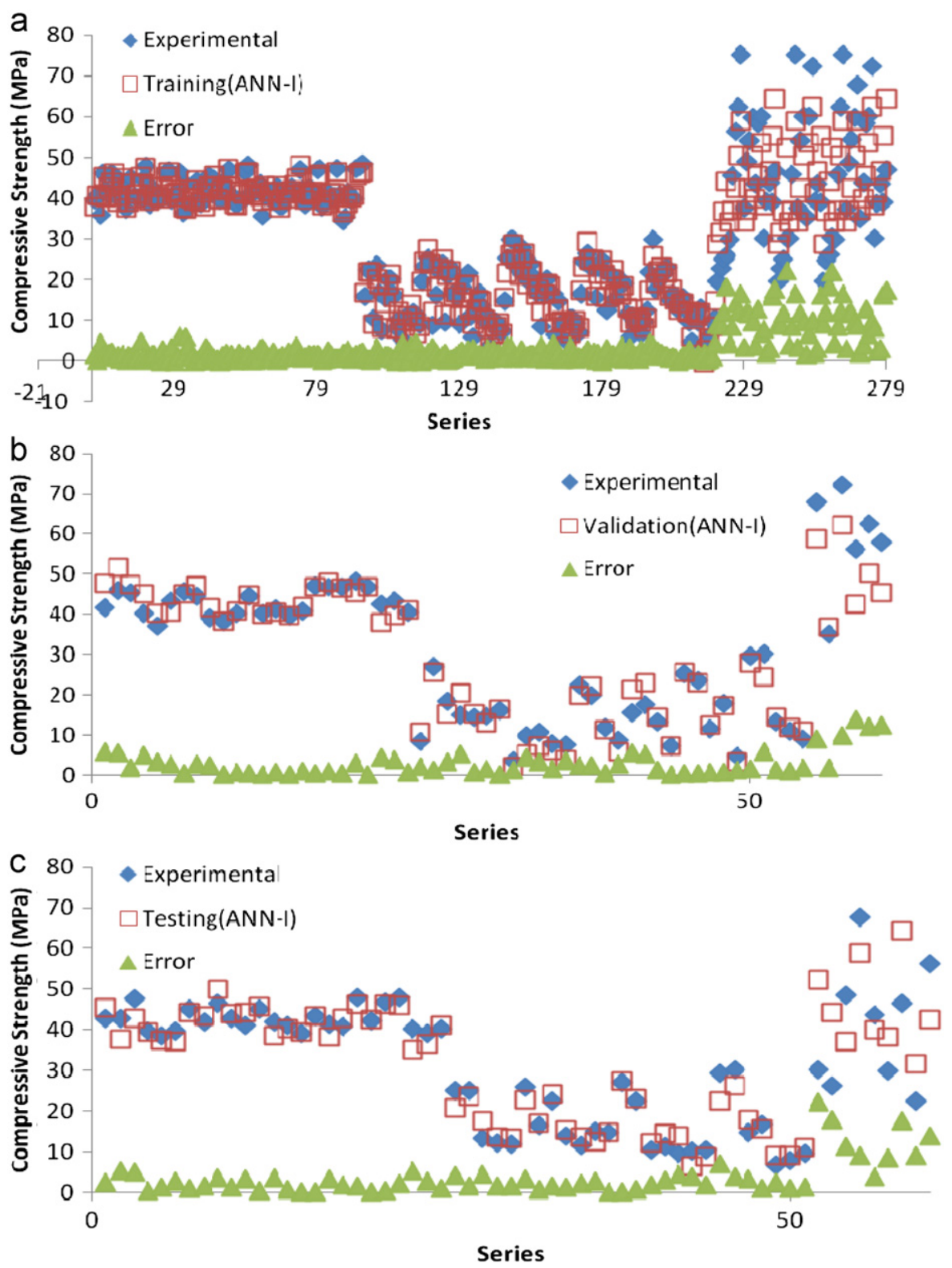

Fig. 2. The correlation of the measured and predicted compressive strength values in (a) training, (b) validating and (c) testing phase for ANN-I model. 
as follows [24]:

$O_{j}=f(\text { net })_{j}=\frac{1}{1+e^{-\alpha\left(\text { net }_{j}\right.}}$

where $\alpha$ is a constant used to control the slope of the semilinear region.

"Typical neural network is reinforced with an advanced training algorithm named as Levenberg-Marquardt backpropagation. The input values to a neuron are obtained by multiplying the output of the connected neuron by the synaptic strength of the connection between them. In this paper, the Levenberg-Marquardt backpropagation (LMBP) algorithm is utilized as a training algorithm instead of the commonly used standard BP method for its robustness in the computing process [25]."

\section{Artificial neural networks parameters and structure}

2-Layer ANNs models, in this research, had seven neurons in the input layer and one neuron in the output layer. The values for input layers were curing time $(T)$, $\mathrm{Ca}(\mathrm{OH})_{2}$ content $(C)$, the amount of superplasticizer $(S)$, $\mathrm{NaOH}$ concentration $(N)$, mold type $(\mathrm{M})$, geopolymer type (G) and $\mathrm{H}_{2} \mathrm{O} / \mathrm{Na}_{2} \mathrm{O}$ molar ratio $(H)$. The value for the output layer was the compressive strength $\left(F_{S}\right)$ values of different geopolymers. Table 1 shows the range of each input parameters and that of the output parameter. A total of six ANNs models were developed by changing the number of neurons in the two considered hidden layers. Table 2 shows the considered number of neurons in each model and Fig. 1 typically shows the structure of ANN-II model. Two-layer terminology was selected because of its
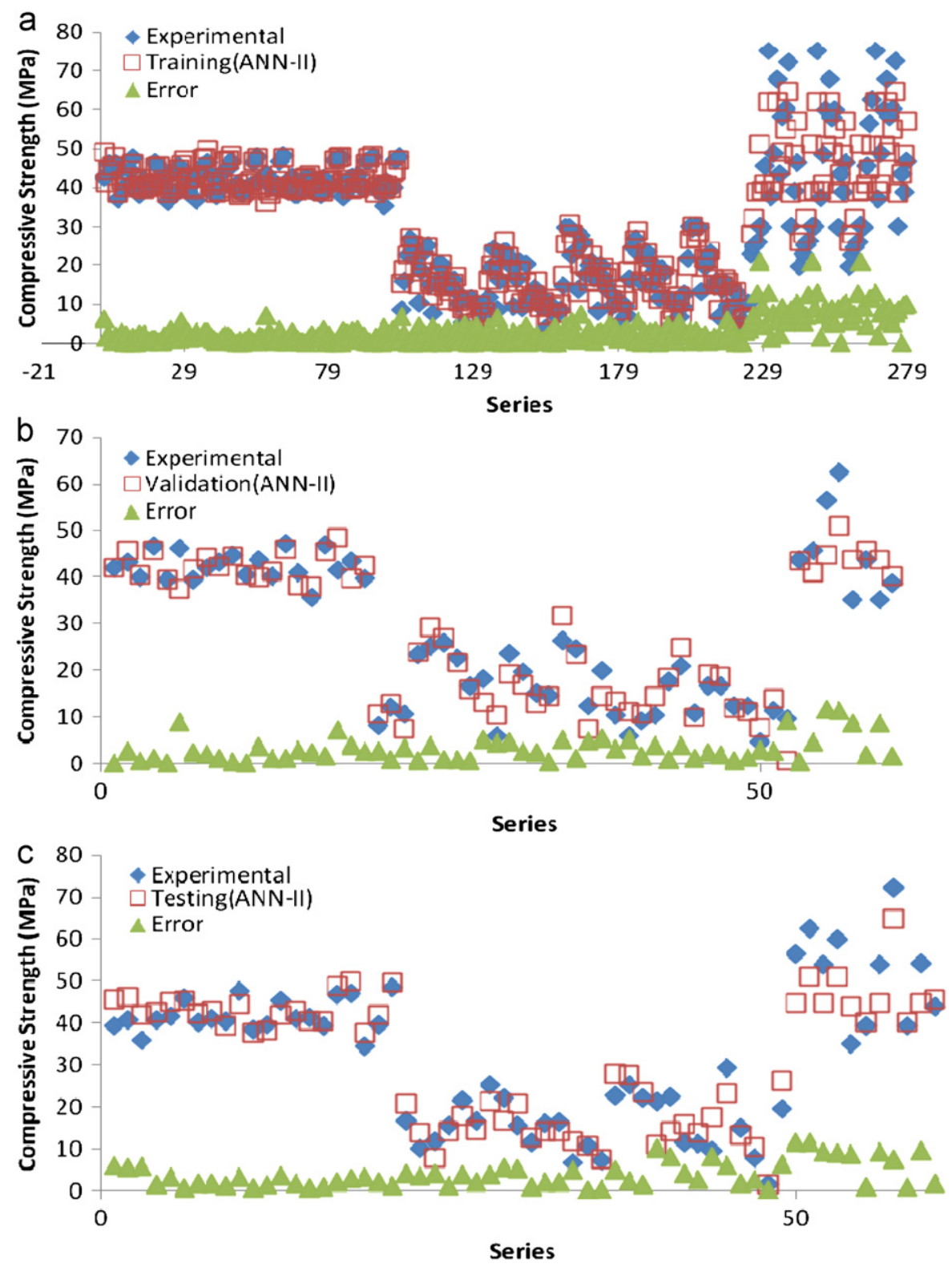

Fig. 3. The correlation of the measured and predicted compressive strength values in (a) training, (b) validating and (c) testing phase for ANN-II model. 
minimum absolute percentage error values for training, validating and testing sets as observed in the author's previous works [26-28]. The neurons of neighboring layers were completely interconnected by weights. Finally, the output layer neurons produce the network prediction as a result.

In this study, the backpropagation training algorithm has been utilized in feed-forward two hidden layers. The backpropagation algorithm, as one of the most wellknown training algorithms for the multilayer perceptron, is a gradient descent technique used to minimize the error of a particular training pattern in which it adjusts the weights by a small amount at a time [29]. The non-linear sigmoid activation function was used in the hidden layer and the neuron outputs in the output layer. Momentum rate and learning rate values were determined and the model was trained through iterations. The trained model was only tested with the input values and the predicted results were close to that of the experiment results. The values of the parameters used in neural network models are given in Table 3 .

A total of 399 values from compressive strength tests in different conditions were collected from the literature $[12,21,22]$ and then trained, validated and tested by means of ANNs. Among the 399 experimental sets, 279 sets were randomly chosen as a training set for the ANN-I to ANN-VI
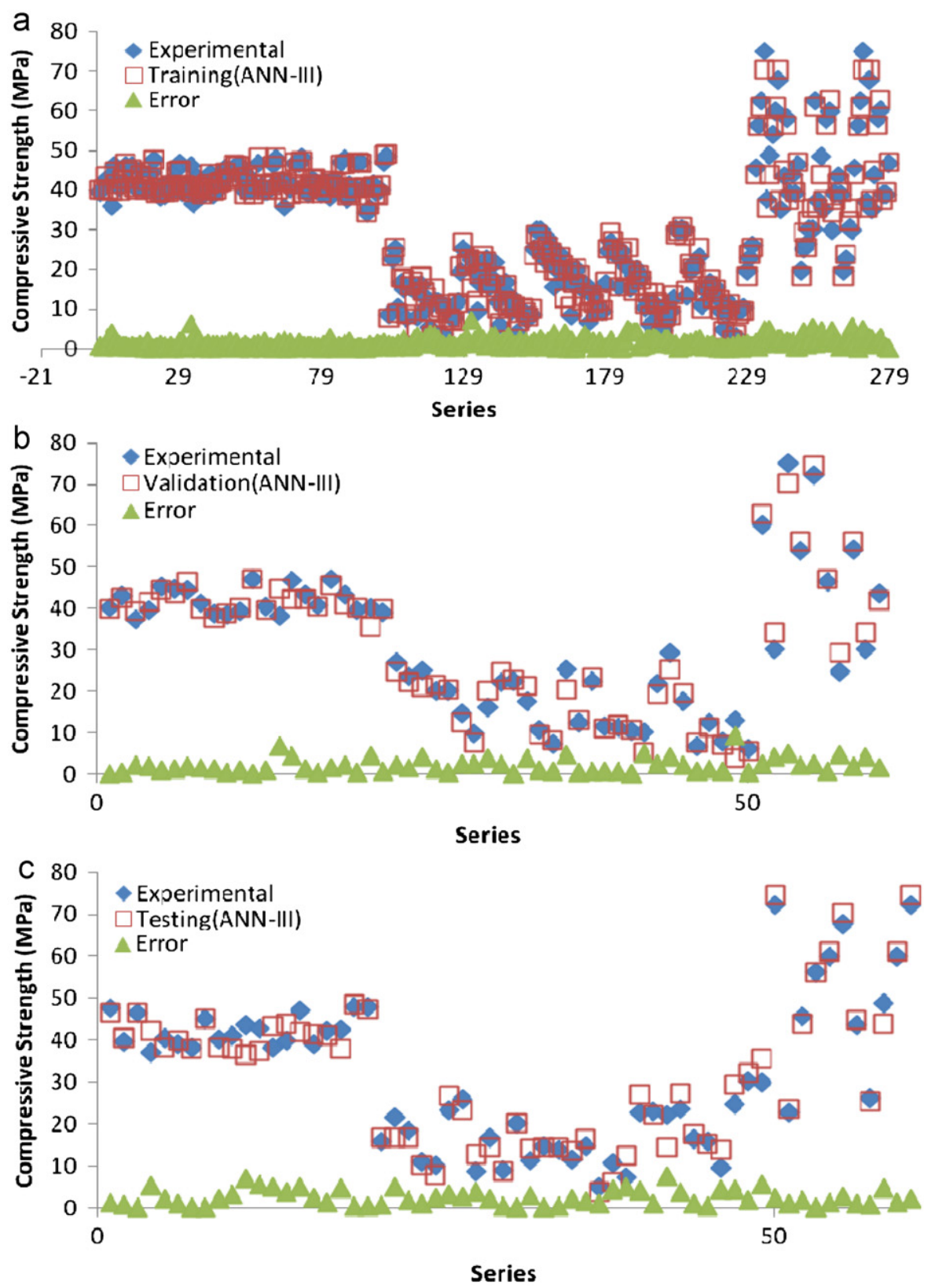

Fig. 4. The correlation of the measured and predicted compressive strength values in (a) training, (b) validating and (c) testing phase for ANN-III model. 
modeling, 60 data sets for validating the constructed networks and the remaining 60 sets were used as testing the generalization capacity of the proposed models.

To make a decision on the completion of the training processes, two termination states are declared: state 1 (ANN-I, ANN-II and ANN-III models) means that the training of neural network was ended when the maximum epoch of process reached (1000) while state 2 (ANN-IV, ANN-V and ANN-VI models) means the training ended when minimum error norm of network gained as indicated in Table 2.

The performance of an ANN model mainly depends on the network architecture and the parameter settings. One of the most difficult tasks in ANN studies is to find this optimal network architecture, which is based on the determination of numbers of optimal layers and neurons in the hidden layers by a trial and error approach. The assignment of initial weights and other related parameters may also influence the performance of the ANN to a great extent. However, there is no well defined rule or procedure to design an optimal network architecture and parameter settings in which the trial and error method still remains valid. This process is, nevertheless, very time consuming [30].

In this study, the Matlab ANN toolbox is used for ANN applications. To overcome optimization difficulty, a program has been developed in Matlab which handles the trial and error process automatically. The program tries various
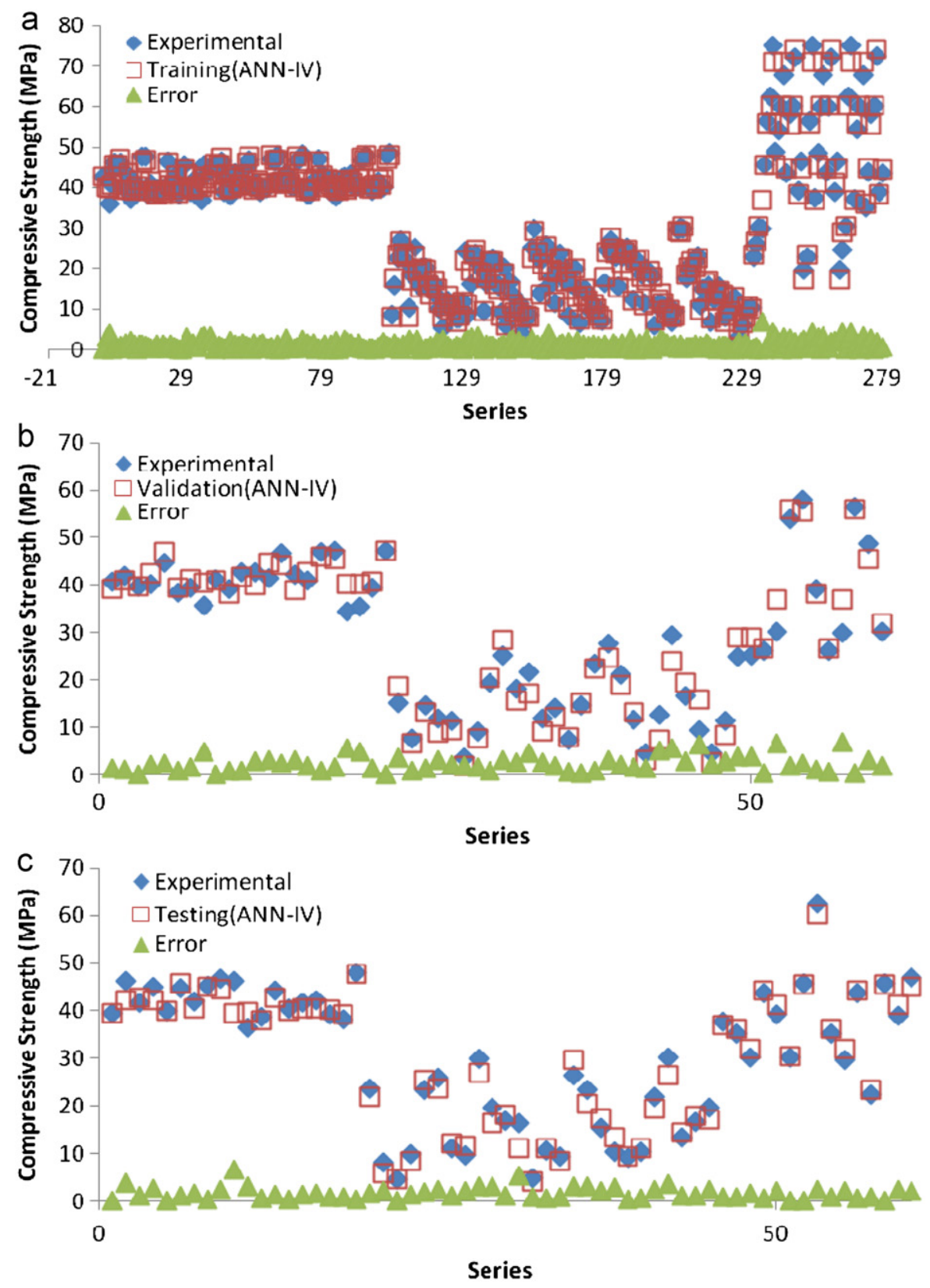

Fig. 5. The correlation of the measured and predicted compressive strength values in (a) training, (b) validating and (c) testing phase for ANN-IV model. 
numbers of layers, and neurons in the hidden layers both for the first and second hidden layers when the highest RMSE (root mean squared error) of the testing and validating sets, as the training set was achieved [30].

\section{Results and discussion}

In this study, the error arose during the training, validating and testing in ANN-I to ANN-VI models. And it can be expressed as absolute fraction of variance $\left(R^{2}\right)$, the absolute percentage error (MAPE) and the root mean square error (RMSE) which are calculated by
Eqs. (3)-(5), respectively [29]:

$$
\begin{aligned}
& R^{2}=1-\left(\frac{\sum_{i}\left(t_{i}-o_{i}\right)^{2}}{\sum_{i}\left(o_{i}\right)^{2}}\right) \\
& \text { MAPE }=\frac{1}{n} \sum_{i}\left|\frac{t_{i}-o_{i}}{t_{i}}\right| \times 100
\end{aligned}
$$

$$
\mathrm{RMSE}=\sqrt{\frac{1}{n} \sum_{i}\left(t_{i}-o_{i}\right)^{2}}
$$

where $t$ is the target value, $o$ is the output value and $n$ is the number of data sets in each of training and testing phases.
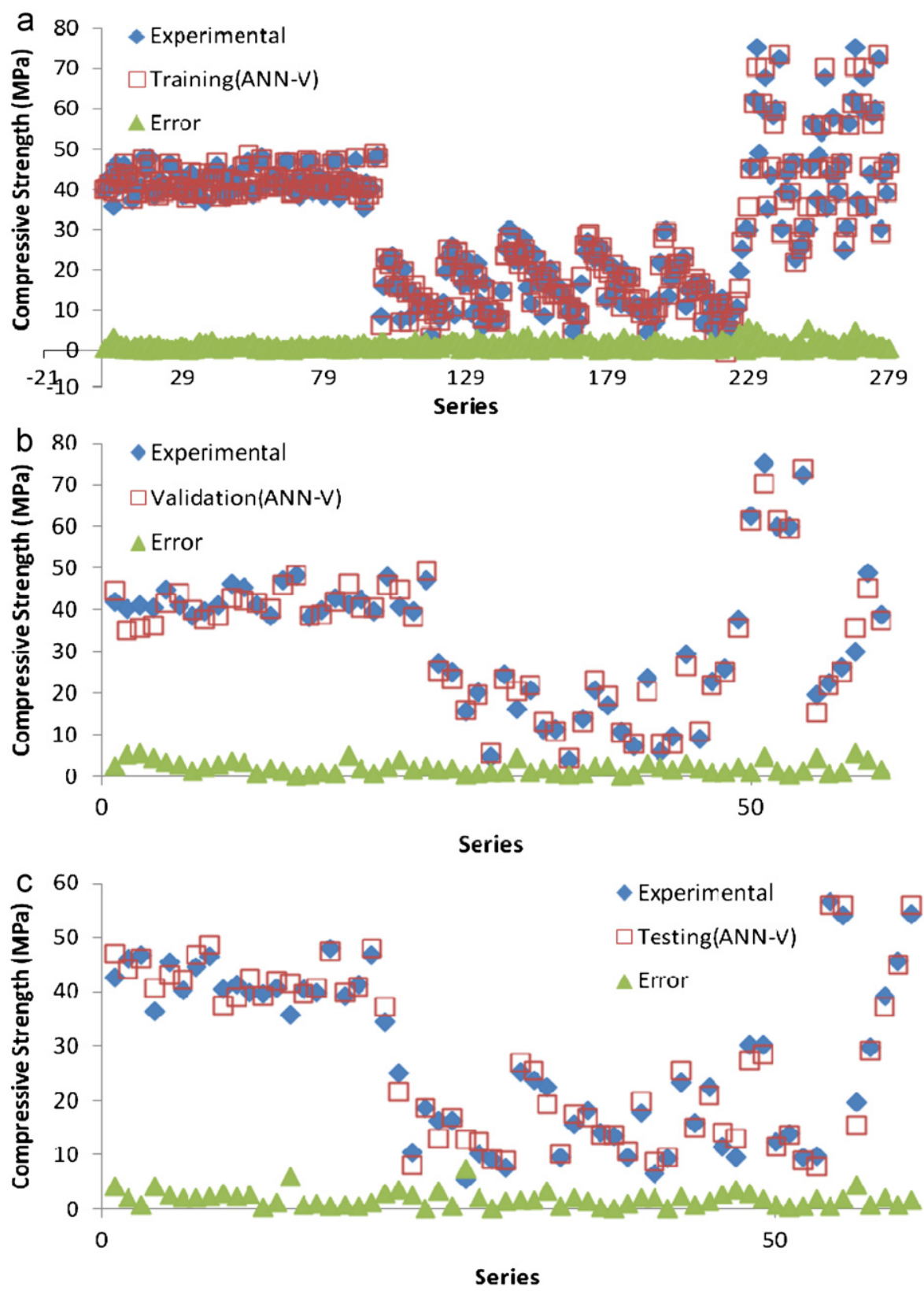

Fig. 6. The correlation of the measured and predicted compressive strength values in (a) training, (b) validating and (c) testing phase for ANN-V model. 
All of the results obtained from the experimental studies and predicted by using the training, validating and testing results of ANN-I to ANN-VI models together with their errors for each data are given in Figs. 2-7, respectively. The linear least square fit line equation, $R^{2}$, MAPE and RMSE values are shown in Table 4 for the training, validating and testing data. As it is visible in Figs. 2-7, the values obtained from the training, validating and testing in ANN-I to ANN-VI models are very close to that of the experimental results.

As Figs. 2-7 show, the predicted results from models are compared to the experimental results for training, testing and validation sets, respectively. Comparing the ANN-I to ANNVI approach models prediction with the experimental results for the testing, validating and training stages demonstrates a high generalization capacity of the proposed models and comparatively low error values. All of these findings exhibit a successful performance of the models for predicting compressive strength values of geopolymers in training, validating and testing stages. Although all of six proposed models show a suitable compatibility between the predicted compressive strength and the experimental one by accuracy of more than $70 \%$, ANN-IV, ANN-V and ANN-VI models illustrate this relationship with more precision. This is due to the method of modeling in which the training is stopped when the minimum absolute error has been acquired. In addition, the ANN-V model reveals better results showing that the number of neurons could affect the training performance of the network
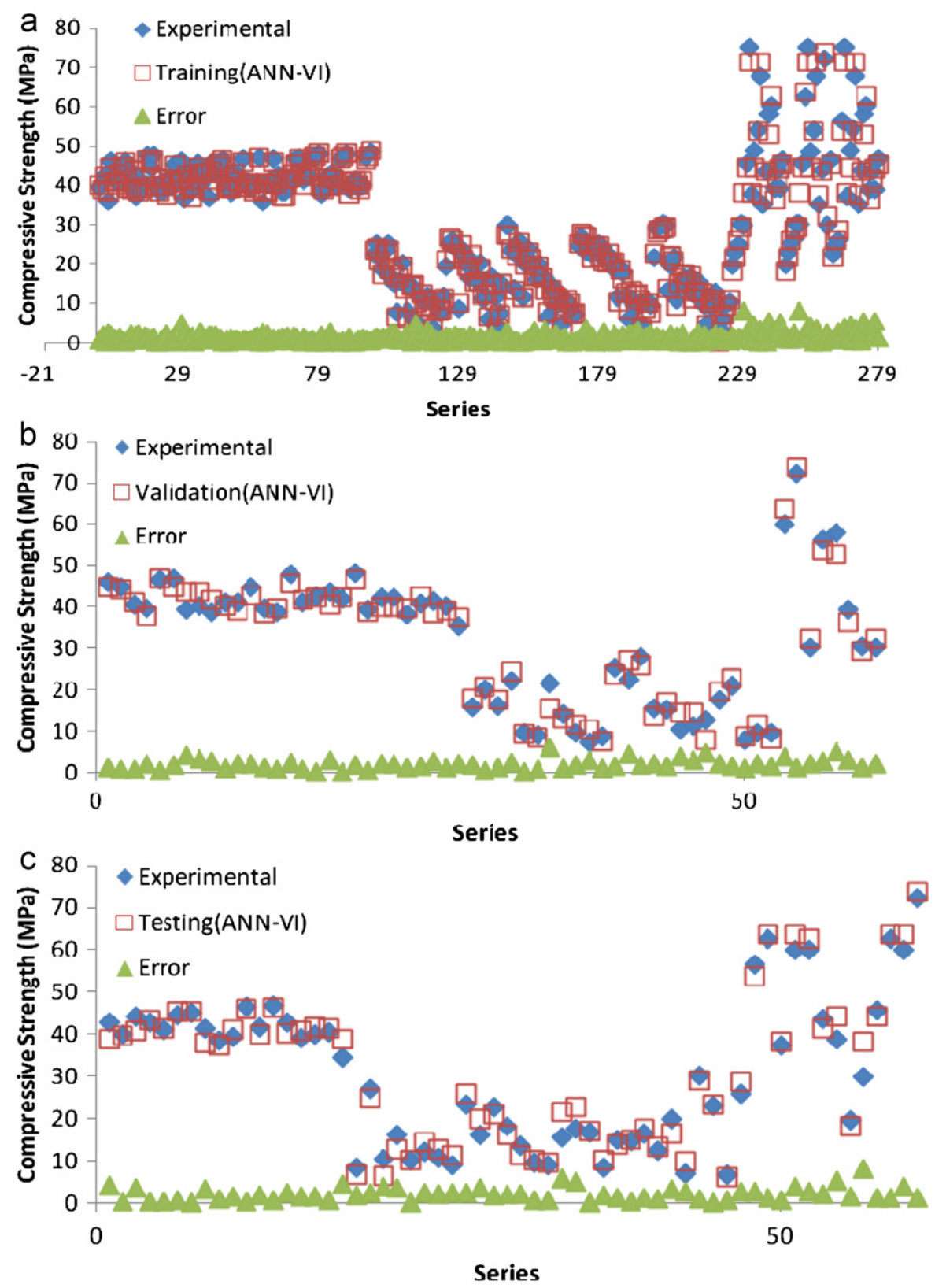

Fig. 7. The correlation of the measured and predicted compressive strength values in (a) training, (b) validating and (c) testing phase for ANN-VI model. 


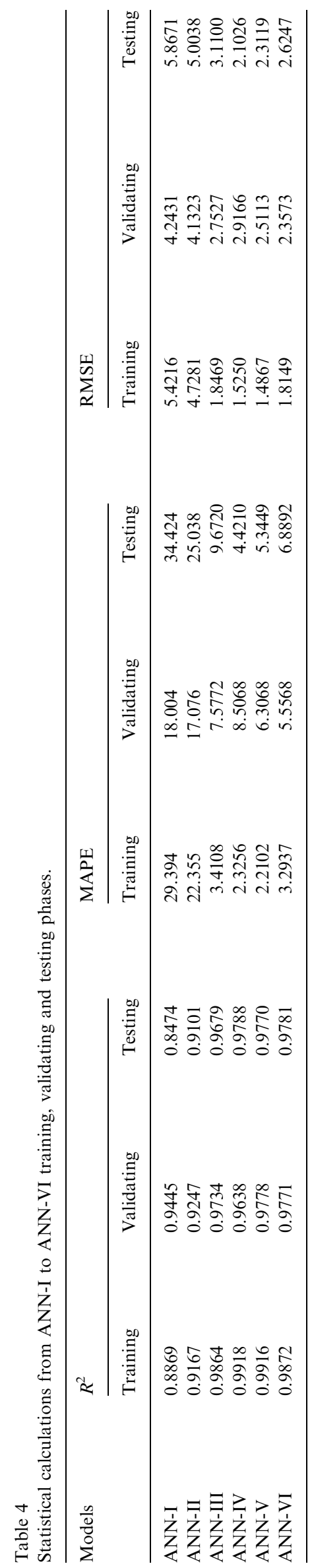

as well as validating and testing. In general, the result of the testing phase in Figs. 2-7 and Table 4 shows that the ANN-III to ANN-VI models are capable of generalizing between input and output variables with reasonably good predictions.

The performance of the ANN-I to ANN-VI models is shown in Table 4. The best value of $R^{2}$ and the minimum values of MAPE and RMSE are 0.9917, 2.2102 and 1.4867 , respectively all in training phase of ANN-IV, $\mathrm{ANN}-\mathrm{V}$ and $\mathrm{ANN}-\mathrm{V}$, in that order. The minimum value of $R^{2}$ and the maximum values of MAPE and RMSE are $0.8474,34.424$ and 5.8671 , respectively all in testing phase of ANN-I model. Although $R^{2}$ values of ANN-I to ANN-VI models show that they are high performance models, high MAPE and RMSE values show that only ANN-III to ANN-VI models are suitable for predicting the compressive strength of geopolymers. On the whole, modeling the compressive strength of geopolymers mainly depends on the training method rather than the number of neurons in hidden layers. However, the number of neurons in hidden layers could slightly affect the performance of the trained, validated and tested networks.

\section{Conclusions}

This study reported a new and efficient approach for the formulation of the compressive strength of different geopolymers. Six different ANN-I to ANN-VI approach models were proposed in order to predict compressive strength values of different geopolymers. The proposed models were empirical and based on experimental results collected from the literature. The models developed in this study were designed to be different in the number of neurons in 2-layer feedforward-backpropagation networks and the method of stopping the training phase. The results obtained from ANN-III to ANN-VI models showed reasonable agreement with collected experimental results from the literature especially when the training phase was stopped when the minimum percentage of absolute error was obtained. The statistical values of MAPE, RMSE and $R^{2}$ revealed this situation. It was found that ANN-III to ANN-VI models can be an alternative approach for the evaluation of the compressive strength of the considered geopolymers. Comparison between ANN-III and ANN-VI models in terms of $R^{2}$, MAPE and RMSE showed that they are capable of predicting suitable results for compressive strength of geopolymers in the considered range. As a result, it was shown that the compressive strength values of different geopolymers can be predicted in ANN-III to ANN-VI models in a relatively short period of time and with tiny error rates.

\section{References}

[1] M.R. Wang, D.C. Jia, P.G. He, Y. Zhou, Microstructural and mechanical characterization of fly ash cenosphere/metakaolin-based geopolymeric composites, Ceramics International 37 (2011) 1661-1666. 
[2] F. Pacheco-Torgal, J.P. Castro-Gomes, S. Jalali, Alkali-activated binders: a review. Part 1. Historical background, terminology, reaction mechanisms and hydration products. Construction and Building Materials 22, 1305-1314.

[3] K. Somna, C. Jaturapitakkul, P. Kajitvichyanukul, P. Chindaprasirt, $\mathrm{NaOH}$-activated ground fly ash geopolymer cured at ambient temperature, Fuel 90 (2011) 2118-2124.

[4] Z. Pan, J.G. Sanjayan, B.V. Rangan, An investigation of the mechanisms for strength gain or loss of geopolymer mortar after exposure to elevated temperature, Journal of Materials Science 44 (2009) 1873-1880.

[5] M. Olivia, H. Nikraz, Properties of fly ash geopolymer concrete designed by Taguchi method, Materials and Design 36 (2012) 191-198.

[6] W.D.A. Rickard, R. Williams, J. Temuujin, A. van Riessen, Assessing the suitability of three Australian fly ashes as an aluminosilicate source for geopolymers in high temperature applications, Materials Science and Engineering A 528 (2011) 3390-3397.

[7] A. Nazari, A. Bagheri., S. Riahi, Properties of geopolymer with seeded fly ash and rice husk bark ash, Materials Science and Engineering A 528 (2011) 7395-7401.

[8] S. Onisei, Y. Pontikes, T. van Gerven, G.N. Angelopoulos, T. Velea, V. Predica, P. Moldovan, Synthesis of inorganic polymers using fly ash and primary lead slag, Journal of Hazardous Materials 205-206 (2012) 101-110.

[9] S. Kumar, R. Kumar, S.P. Mehrotra, Influence of granulated blast furnace slag on the reaction, structure and properties of fly ash based geopolymer, Journal of Materials Science 45 (2010) 607-615.

[10] F. Özcan, C.D. Atiş, O. Karahan, E. Uncuoğlu, H. Tanyildizi, Comparison of artificial neural network and fuzzy logic models for prediction of long-term compressive strength of silica fume concrete, Advances in Engineering Software 40 (2009) 856-863.

[11] P. Duxson, S.W. Mallicoat, G.C. Lukey, W.M. Kriven, J.S.J. van Deventer, The effect of alkali and $\mathrm{Si} / \mathrm{Al}$ ratio on the development of mechanical properties of metakaolin-based geopolymers, Colloids and Surfaces A: Physicochemical and Engineering Aspects 292 (2007) 8-20.

[12] F. Pacheco-Torgal, D. Moura, Yining Ding, S. Jalali, Composition, strength and workability of alkali-activated metakaolin based mortars, Construction and Building Materials 25 (2011) 3732-3745.

[13] J. He, J. Zhang, Y. Yu, G. Zhang, The strength and microstructure of two geopolymers derived from metakaolin and red mud-fly ash admixture: a comparative study, Construction and Building Materials 30 (2012) 80-91.

[14] A. Poulesquen, F. Frizon, D. Lambertin, Rheological behavior of alkali-activated metakaolin during geopolymerization, Journal of Non-Crystalline Solids 357 (2011) 3565-3571.

[15] M. Saridemir, Prediction of compressive strength of concretes containing metakaolin and silica fume by artificial neural networks, Advances in Engineering Software 40 (2009) 350-355.

[16] I.B. Topçu, M. Sarıdemir, Prediction of compressive strength of concrete containing fly ash using artificial neural networks and fuzzy logic, Computational Materials Science 41 (2008) 305-311.
[17] C. Bilim, C.D. Atiș, H. Tanyildizi, O. Karahan, Predicting the compressive strength of ground granulated blast furnace slag concrete using artificial neural network, Advances in Engineering Software 40 (2009) 334-340.

[18] A. Nazari, Artificial neural networks to prediction compressive strength of geopolymers with seeded waste ashes, Neural computing and Applications (2012) http://dx.doi.org/10.1007/s00521-012-0931-4.

[19] A. Nazari, Artificial neural networks application to predict the compressive damage of lightweight geopolymer, Neural computing and Applications (2012) http://dx.doi.org/10.1007/s00521-012-0945-y.

[20] S. Riahi, A. Nazari, Prediction the effects of nanoparticles on early age compressive strength of ash-based geopolymers by artificial neural networks, Neural computing and Applications (2012) http:// dx.doi.org/10.1007/s00521-012-1085-0.

[21] F. Pacheco-Torgal, J.P. Castro-Gomes, S. Jalali, Investigations on mix design of tungsten mine waste geopolymeric binder, Construction and Building Materials 22 (2008) 1939-1949.

[22] F. Pacheco-Torgal, J. Castro-Gomes, S. Jalali, Investigations about the effect of aggregates on strength and microstructure of geopolymeric mine waste mud binders, Cement and Concrete Research 37 (2007) 933-941.

[23] X. Kong, A.M. Khambadkone, Modeling of a PEM fuel-cell stack for dynamic and steady-state operation using ANN-based submodels, IEEE Transactions on Industrial Electronics 56 (12) (2009) 4903-4914.

[24] M. Sarıdemir, I.B. Topcu, F. Ozcan, M.H. Severcan, Prediction of long-term effects of GGBFS on compressive strength of concrete by artificial neural networks and fuzzy logic, Construction and Building Materials 23 (2009) 1279-1286.

[25] J. Sobhani, M. Najimi, A.R. Pourkhorshidi, T. Parhizkar, Prediction of the compressive strength of no-slump concrete: a comparative study of regression, neural network and ANFIS models, Construction and Building Materials 24 (2010) 709-718.

[26] A. Nazari, S. Riahi, Prediction split tensile strength and water permeability of high strength concrete containing $\mathrm{TiO}_{2}$ nanoparticles by artificial neural network and genetic programming, Composites Part B: Engineering 42 (2011) 473-488.

[27] A. Nazari, Application of artificial neural networks for analytical modeling of Charpy impact energy of functionally graded steels, Neural Computing and Applications (2011) http://dx.doi.org/10.1007/s00521011-0761-9.

[28] A. Nazari, A. Sedghi, N. Didehvar, Modeling impact resistance of aluminum-epoxy laminated composites by artificial neural networks, Journal of Composite Materials 46 (13) (2012) 1593-1605.

[29] A.A. Suratgar, M.B. Tavakoli, A. Hoseinabadi, Modified Levenberg-Marquardt method for neural networks training, World Academy of Science, Engineering and Technology 6 (2005) 46-48.

[30] I.H. Guzelbey, A. Cevik, A. Erklig, Prediction of web crippling strength of cold-formed steel sheetings using neural Networks, Journal of Constructional Steel Research 62 (2006) 962-973. 